remembrance of the Boston healthcare lawyer Ben Schwartz, Schwartz Rounds are a multidisciplinary forum in which a panel of clinical and sometimes non-clinical staff are invited to discuss the emotional and social aspects of healthcare. They are normally structured around the recounting of an experience around a particular title/theme, for example, "A patient I'll never forget" $(19,20)$. It is important to note that Schwartz Rounds differ from traditional clinical "grand rounds" or "debriefs" as their focus is not on clinical aspects of care/practice or problem solving $(19,20)$.

\section{References}

1. Francis R (Chair). Report of the Mid Staffordshire NHS Foundation Trust Public Inquiry. London: Her Majesty's Stationary Office; 2013. Available from: https://www.gov.uk/government/publications/report-of-themid-staffordshire-nhs-foundation-trust-public-inquiry

2. Bolsin S, Pal R, Wilmshurst P, Pena M. Whistleblowing and patient safety: the patient's or the profession's interests at stake? J R Soc Med. 2011 Jul;104(7):278-82.

3. Mid Staffordshire NHS Foundation Trust Public Inquiry. Nurs Stand. 2010 Oct;25(7): 30.

4. Kaptein M. From inaction to external whistleblowing: The influence of the ethical culture of organizations on employee responses to observed wrongdoing. J Bus Ethics. 2011 Feb;98(3):513-30.

5. Francis R. Freedom to speak up: an independent review into creating an open and honest reporting culture in the NHS [Internet]. Natl Arch. 2015 Feb 11[cited 2018 Aug 23]. Available from: http://webarchive. nationalarchives.gov.uk/20150218150953/https://freedomtospeakup. org.uk/wp-content/uploads/2014/07/F2SU_web.pdf

6. Cohen D. Back to blame: the Bawa-Garba case and the patient safety agenda. BMJ 2017 Nov 29;359:j5534.

7. Evans L.Why there are business benefits to encouraging whistleblowers. Wales Online. 2014 Apr 6 [cited 2018 Aug 23]. Available from: http:// www.walesonline.co.uk/business/business-opinion/business-benefitsencouraging-whistleblowers-6925451

8. Mansbach A, Ziedenberg H, Bachner YG. Nursing students' willingness to blow the whistle. Nurse Educ Today. 2013 Jan;33(1):69-72.

9. Mansbach A, Melzer I, Bachner YG. Blowing the whistle to protect a patient: a comparison between physiotherapy students and physiotherapists, Physiotherapy. 2012 Dec;98(4):307-12.

10. Hodges LE, Tak HJ, Curlin FA, Yoon JD.Whistle-blowing in medical school: A national survey on peer accountability and professional misconduct in medical students. Acad Psychiatry. 2016;40(3):530-3.

11. Martin P. The status of whistleblowing in South Africa: taking stock [Internet]. Open Democracy Advice Centre; 2010 Jun [cited 2018 Aug 23]. Available from: http://www.advocacyaid.com/images/stories/ rrdownloads/ODAC_Whistleblowing_Report.pdf

12. Healthcare in South Africa [Internet]. Brand South Africa. 2012 Jul 2 [cited 2018 Aug 23]. Available from: https://www.brandsouthafrica.com/ south-africa-fast-facts/health-facts/health-care-in-south-africa

13. Saunders B, Sim J, Kingstone T, Baker S, Waterfield J, Bartlam B, Burroughs $\mathrm{H}$, Jinks $\mathrm{C}$. Saturation in qualitative research: exploring its conceptualization and operationalization. Qual Quant. 2018 Jul;52(4):1873-1907.

14. Lim CR, Zhang MWB, Hussain SF, Ho RCM. The consequences of whistleblowing: an integrative review. J Patient Saf. 2017 Jun 30. doi: 10.1097/ PTS.0000000000000396. [Epub ahead of print]

15. Pohjanoksa J, Stolt M, Suhonen R, Löyttyniemi E, Leino-Kilpi H. Whistleblowing process in healthcare: from suspicion to action. Nurs Ethics. 2017 Jan 1; 69733017705005. doi: 10.1177/0969733017705005. [Epub ahead of print]

16. Chatterjee P.Whistleblowing in India: what protections can doctors who raise concerns expect? BMJ. 2015 Feb 4;350:h763.

17. Mansbach A,KushnirT,Ziedenberg H,Bachner YG. Reporting misconduct of a coworker to protect a patient: a comparison between experienced nurses and nursing students. ScientificWorldJournal. 2014;2014:413926.

18. Loyens $K$, Maesschalck J.Whistleblowing and power. In:Brown A J, Lewis D, Moberly R, Vandekerckhove W, editors. International handbook on whistleblowing research. Northampton: Edward Elgar Publishing; 2014. p. 154-74.

19. The Schwartz Center for Compassionate HealthCare [Internet]. Boston: The Schwartz Center; c2018 [cited 2018 May 30]. Available from: http:// www.theschwartzcenter.org/

20. About Schwartz Rounds [Internet]. London: The Point of Care Foundation UK; n.d. [cited 2018 May 30]. Available from: https://www. pointofcarefoundation.org.uk/our-work/schwartz-rounds/aboutschwartz-rounds/

\title{
Teaching ethics using games: Impact on Iranian nursing students' moral sensitivity
}

\section{MARYAM MADDINESHAT, MOHAMMAD REZA YOUSEFZADEH, MAHDI MOHSENI, ZAHRA MAGHSOUDI, MOHAMMAD EBRAHIM GHAFFARI}

Authors: Maryam Maddineshat (corresponding author- m.madineshat@ umsha.ac.ir), PhD Student in Nursing, Department of Nursing, School of Nursing, Hamadan University of Medical Sciences, Hamadan, IRAN; Mohammad Reza Yousefzadeh (Nimrooz@basu.ac.ir) Associate Professor, Bu Ali Sina University, Collage of Humanities, Department of Education, Hamadan, IRAN; Mahdi Mohseni (mohseni_m1989@yahoo.com) MSc (Nurse), Department of Nursing, School of Nursing, Hamadan University of Medical Sciences, Hamadan, IRAN; Zahra Maghsoudi (maghsoudi.zahra89@ gmail.com) PhD Student in Nursing, Student Research Committee, Hamadan University of Medical Sciences, Hamadan, IRAN; Mohammad Ebrahim Ghaffari (m.gh19@yahoo.com) PhD Student in Biostatistics, Dental Sciences, Research Center, Faculty of Dentistry, Guilan University of Medical Sciences, Rasht, IRAN

To cite: Maddineshat M, Yousefzadeh MR, Mohseni M, Maghsoudi Z, Ghaffari ME. Teaching ethics using games: Impact on Iranian nursing students' moral sensitivity. Indian J Med Ethics. 2019 Jan-Mar: 4(1)NS:14-20. DOI:10.20529/ IJME.2018.056.

Published online on July 14, 2018.

Manuscript Editor:Vijayaprasad Gopichandran

() Indian Journal of Medical Ethics 2018

\section{Abstract}

This study seeks to develop a method of teaching ethics to nursing students using games. We used the one-group pretest-posttest design with 30 undergraduate nursing students as participants. Professional ethics education was provided for 17 weeks in 90-minute sessions. The Lutzen ethical sensitivity questionnaire and a checklist of the satisfaction levels of games used measured the effects of training. Repeated-measures ANOVA and the Greenhouse-Geisser correction were used to measure ethics game satisfaction. After training, total moral sensitivity questionnaire scores increased significantly $(p=0.02)$. The score on awareness of the relationship with the patient and the application of ethics concepts in ethical decisions from the subdomain of moral sensitivity increased significantly. Card sorting and drawing or art production earned the highest scores of satisfaction. The results show that playing games is a useful approach to developing 
moral sensitivity among nursing students to make them more sensitive toward ethics issues in their professional environment.

\section{Introduction}

Nurses must develop the skills of critical thinking, decision making, and conflict resolution and the ability to support the populations they care for. They require ethics education at all levels of their professional life (1). It is vital to impart ethics education that can be put to actual use and not simply focus on teaching it in the classroom. Ethics is a dynamic field; it is not something one learns once and then forgets. Ethics is learned through case studies that clarify values and their application. A rich literature describes how nurses are confronted with ethical challenges (2). It must be determined whether or not Iranian nursing students are ready to face the ethical challenges of their careers. The short answer to this question is "No"(3). Studies emphasise that nursing is ethics based and ethics are fundamental to nursing care $(4,5)$.

Previous studies also reported that ethics training for nursing students aimed at developing moral sensitivity and enhancing their understanding of professional ethics (6). Moral sensitivity is the basis of ethics for nurses to enable them to provide effective and ethical care to their patients. Moral sensitivity makes nurses perceptive of ethical issues in their professional environment and enables them to make ethical decisions for their patients (7). It is a characteristic that can be developed by teaching professional ethics, including: legal issues, nursing professionalism, human rights, physician-nurse-patient communication, and ethical aspects of decision making. Moral sensitivity does not necessarily include all aspects of professional ethics; however, teaching professional ethics promotes this characteristic (ie, moral sensitivity), which prepares students to deal with moral challenges in the clinic and helps them make ethical decisions (8).

Professional ethics has roots in philosophy. The teaching of sessions by the lecture method is not interesting to the students and is tiring for both the students and the educators $(9,10)$. Previous studies show that the teaching method has a significant effect on the development of the students' moral sensitivity $(3,11)$; therefore, combining games with professional ethics can make the teaching of professional ethics interesting, create a happy environment for learning, and enhance the students' moral sensitivity (12).

The use of games is an innovative method, that according to the researchers, may improve student learning outcomes. The use of games can improve learning, encourage critical thinking, and make learning more exciting. In fact, a game can draw on real-life scenarios; however, few studies support this approach(13). Moreover, with developments in science and increasing ethical challenges facing healthcare centres, more and more modern methods such as games can be used to identify and deal with ethical challenges(14). Therefore, the purpose of the current study was to determine the impact of teaching ethics using games on Iranian nursing students' moral sensitivity.

\section{Methods}

\section{Design and subjects}

This quasi-experimental study was carried out as one-group pretest-posttest. The participants in the study were students of Malayer Nursing Faculty in western Iran. After approval from the Malayer School of Nursing Education (P/16/79/1136/2016), $\mathrm{n}=30$ nursing students in their fourth semester of nursing school were selected through non-probability sampling to participate from January 2016 to May 2017.

In Iran, the academic year comprises two semesters. Each semester is seventeen weeks, running from September to December and from January to May. Based on the curriculum regulated and approved by the Board of Nursing under Ministry of Health, Treatment and Medical Education, the duration of the nursing course is four years in Iran, and nursing students have the professional ethics lesson in their second year of study, in the fourth semester. Therefore, at the time of the study, only students who were studying in the fourth semester and had a professional ethics course could participate in this study. In Iran, in the fourth semester, a 1.5 credit professional ethics course is taught to nursing students theoretically and practically. Nursing students enter clinical education in the second semester, and practical courses are taught alongside theoretical courses. Therefore, they have already encountered ethical challenges in the clinical environment.

\section{Ethical considerations}

Ethical approval was taken from the Malayer School of Nursing Education Center for Hamadan University of Medical Sciences vide letter no. (P/16/79/1136), dated 4/02/2016. A signed, voluntary participation consent form was obtained from all students, and the students were assured that their responses would not affect their grades and would be kept completely confidential and anonymous. A coding system was used to keep the information confidential. If desired, the results of the study were communicated to the participants.

\section{Intervention}

It was initially explained to the students how nursing ethics would be taught so that they could participate in the teaching process. Based on the nursing education programme and rules and regulations of Iranian Nursing Faculties, nursing students get their professional ethics course only in their fourth semester, so we didn't have any intervention with the selected nursing students. Of the 30 nursing students who participated in this study, 14 were women (53.3\%) and 16 were men (46\%) [In Iran more women are accepted in faculties in the nursing discipline]. Previous studies show teachers use the small group technique as a way of dividing up larger classes, involving students in smaller groups working together. But there is no one right size for a group $(15,16)$. In this study students were divided into 7 groups ( 3 groups with male students and 4 with female students). The nursing ethics sessions were held once a week for 17 weeks, 90 minutes each. Owing to the 
nature of the games, a number of the games were held in two sessions, and this was due to the need for the professional role of the teacher in explaining the game. The ethics training programme selected for each session (Table 1) was in line with the new curriculum of nursing approved by the Ministry of Health and Treatment and Medical Education of Iran in $2013(17,18)$, and is therefore a valid teaching programme.

The contents of each session were prepared by the teacher using MS PowerPoint and sent to the students using mobile technology. The students were expected to study the matter before the beginning of each class. If the students needed to review previously taught content during the game, they could refer to the educational content on their mobile device.

A combination of problem solving and gameplay was used to teach the contents of each session. The lessons were designed to focus on ethical scenarios and questions about health care by the use of games and competition between students when responding to scenarios. The book Moral Games for Teaching Bioethics published by the UNESCO (United Nations Educational, Scientific and Cultural Organization) Chair in Bioethics (19) was adopted as the guide for teaching this course. Twelve games were selected from this book in accordance with the content planned for each session.

As nursing education in Iran is taught in Persian, at first the game content was designed by the researchers of the current study, and the twelve selected games from the book Moral Games were translated into Persian. Then, a panel with the members of the Ethics Committee of the Malayer School of Nursing checked the educational content of the game according to the requirements for medical studies and moderated according to Iranian culture. These panels were held in three sessions of two hours each.

The educational content was taught by one of the ethics educators at the Malayer School of Nursing, where the study was conducted. The educators were selected by the institutional ethics committee, who had a history of teaching in nursing ethics. The content was provided to the educators, and their task was to teach nursing students throughout the study. The educators were unaware of the fact that they were part of this study. The researchers provided questionnaires to nursing students before and after the training.

\section{Measurement of moral sensitivity}

The sampling tools included the Moral Sensitivity Questionnaire developed by Lutzen in Sweden in 1994 and amended in 1997 and 2003(20, 21). The Moral Sensitivity Questionnaire in Iran has been translated into Persian and adapted to Iranian culture (22). Its validity and reliability have been measured in Iranian studies by Abbaszadeh et al. and Karimi Noghondar et al. The Cronbach's alpha coefficient of this questionnaire has been reported in Iranian studies as $\alpha=0.7(22,23)$.

The questionnaire consists of two parts. The first part addresses demographic information, and the second part has 25 questions that measure the degree of moral sensitivity. The questionnaire uses a five-point Likert scale from 0 (complete opposition) to 4 (complete agreement). The highest score possible is 100 , and the lowest possible score is 0 . A total score between 0 and 50 denotes low moral sensitivity, between 51 and 75, moderate moral sensitivity, and between 76 and 100, high moral sensitivity. The questionnaire has six dimensions: patient autonomy (questions 10, 12, and 13); relational orientation with the patient (questions 1-4, and 17); professional knowledge (questions 16 and 24); experiencing problems and moral conflict (questions 9, 11, and 15); applying ethical meaning to ethical decisions (questions $6,8,14$, and 20); and expressing benevolence (questions 5, 7, 19, 21-23, and 25) (24)

\section{Measurement of student satisfaction with ethics games}

Since teaching professional ethics in the form of games is a new concept, a checklist was provided on the teaching methods of the authors in order to receive feedback from the students(25). This consisted of 17 checklist questions that can assess satisfaction with the 12 games played over the course of 17 sessions. The questions were scored using a five-part Likert scale ranging thus: very dissatisfied -1 , dissatisfied -2 , neither satisfied nor dissatisfied -3 , satisfied -4 , and very satisfied -5 . A checklist was also developed to measure student satisfaction with the content taught in each session using a Likert score. The validity of this questionnaire was confirmed by faculty members.

\section{Data analysis}

The mean and standard deviation were used for describing quantitative data and for qualitative data, the number and percentage were used. To compare the moral sensitivity scores before and after education, the paired t-test and chisquare test were used to correlate ethical sensitivity by gender. Repeated-measures ANOVA and the Greenhouse-Geisser correction were used to measure satisfaction with the ethics game. The results were considered to be significant at $p<0.05$. Data analysis was performed using SPSS16 software.

\section{Results}

\section{General characteristics of nursing students}

The average age of participants was 21 years $(22.17 \pm 5.28)$. Of those, $93.3 \%$ had not attended an ethics workshop before.

\section{Effects of teaching nursing ethics using games on moral sensitivity}

The results of the moral sensitivity questionnaire are shown in Table 2. The mean score of moral sensitivity was $66.43 \pm$ 5.85 for female students and $62.94 \pm 7.5$ for male students. There was no significant difference between gender and student moral sensitivity scores using the chi-square test $(p=$ 0.06). The total score for moral sensitivity before and after the intervention showed statistically significant changes. The range of moral sensitivity scores of nursing students fell into the medium and high ranges (93.3\% to $96.7 \%$ ). 


\begin{tabular}{|c|c|c|}
\hline $\begin{array}{l}\text { Session } \\
\text { number }\end{array}$ & Main themes & Teaching method \\
\hline 1 & $\begin{array}{l}\text { - Professional ethics in the health system } \\
\text { - Definition of nursing ethics and its } \\
\text { importance }\end{array}$ & $\begin{array}{l}\text { Buzz group Game: } \\
\text { Explain to students the purpose of study; students divided into small groups; } \\
\text { students asked to answer ethics questions from the content of the session; top group } \\
\text { given a prize. }\end{array}$ \\
\hline 2 & $\begin{array}{l}\text { - Philosophy of ethics in the medical sciences } \\
\text { - History of nursing ethics and human relations }\end{array}$ & $\begin{array}{l}\text { The Brainstorming Game: } \\
\text { Development of moral questions from the content of the session. } \\
\text { Groups compete to answer questions. }\end{array}$ \\
\hline 3 & - Bioethics & $\begin{array}{l}\text { The Card Sorting Game: Students asked to design and present flashcards of bioethical } \\
\text { principles and case studies. Prize given to the top group. }\end{array}$ \\
\hline 4 & $\begin{array}{l}\text { - Moral sensitivity in nursing education } \\
\text { (clinical) }\end{array}$ & $\begin{array}{l}\text { The Health Journey Game: Students encouraged to discuss in pairs the gap in } \\
\text { treatment patients have experienced during clinical training sessions. }\end{array}$ \\
\hline 5 & $\begin{array}{l}\text { Types of physician-nurse-patient } \\
\text { communication models }\end{array}$ & $\begin{array}{l}\text { Lecture and explanation of types of physician-nurse-patient communication models. } \\
\text { Students asked to write scenarios about the physician-nurse-patient relationship in } \\
\text { groups with instructor supervision for the Role Playing Game. }\end{array}$ \\
\hline 6 & $\begin{array}{l}\text { - Types of physician-nurse-patient } \\
\text { communication models }\end{array}$ & $\begin{array}{l}\text { The Role Playing Game: Students asked to depict a physician-nurse-patient model } \\
\text { by role play. Prize given to the top group. }\end{array}$ \\
\hline 7 & - Ethical aspects of decision-making & $\begin{array}{l}\text { The Talking-in-Pairs Game: Students asked to complete the Decision-Making } \\
\text { Guidelines for Licensed Practical Nurses in Canada supervised by two instructors. } \\
\text { Prize given to the top group. }\end{array}$ \\
\hline 8 & - Ethical aspects of decision-making & $\begin{array}{l}\text { Lecture, analysis of student assignments from previous session, and provision of } \\
\text { feedback. }\end{array}$ \\
\hline 9 & $\begin{array}{l}\text { - Professional nursing responsibilities based on } \\
\text { ethical standards }\end{array}$ & $\begin{array}{l}\text { Lecture and explanation of professional responsibilities of nurses; scenario writing for } \\
\text { Hot-Seat Game. }\end{array}$ \\
\hline 10 & $\begin{array}{l}\text { - Professional nursing responsibilities based on } \\
\text { ethical standards }\end{array}$ & $\begin{array}{l}\text { The Hot-Seat Game: Small groups asked to design four moral questions with } \\
\text { answers from the text. Then get one member from each group to come up and sit } \\
\text { in that chair, so they are facing their team-mates and have their back to the board. } \\
\text { The student in the hot seat listens to their team mates and tries to answer moral } \\
\text { questions. Then change the students over, with a new member of each team taking } \\
\text { their place in their team's hot seat. Prize given to the top group. }\end{array}$ \\
\hline 11 & - Moral and legal issues in nursing & $\begin{array}{l}\text { The Drawing or Production Art Game: Students paint their seven nursing standards } \\
\text { on a balloon and draw basic ethics principles and themes in nursing ethics and } \\
\text { present them. Prize given to the top group. }\end{array}$ \\
\hline 12 & - Moral and legal issues in nursing & $\begin{array}{l}\text { The Socratic Debate Game: Ethics concepts and rules taught using films; groups } \\
\text { instructed to contest, discuss, and analyse films amongst themselves. Prize given to } \\
\text { the top group. }\end{array}$ \\
\hline 13 & - Special professional offenses and penalties & $\begin{array}{l}\text { The Passing the Parcel Game: Class divided into } 7 \text { groups. Two gifts, one for each } \\
\text { group, are wrapped in layers of paper and used to play "passing the parcel". Each time } \\
\text { the music stops, students must unwrap one layer of paper and answer the question } \\
\text { on it related to specific professional offenses. } \\
\text { Prize given to the top group. }\end{array}$ \\
\hline 14 & - Special professional offenses and penalties & Pass the parcel game. \\
\hline 15 & $\begin{array}{l}\text { - Understanding human rights and respecting } \\
\text { the rights of the patient }\end{array}$ & $\begin{array}{l}\text { The Case Study Game: The instructor writes case scenarios from the session content, } \\
\text { and the groups compete to respond to scenarios. } \\
\text { Prize given to the top group. }\end{array}$ \\
\hline 16 & - Professional nursing ethics codes & $\begin{array}{l}\text { Field Visits / Educational Visits Game: The Code of Ethics for Nursing in Iran is } \\
\text { introduced. Teachers take students to the hospital and split them up into } 7 \text { small } \\
\text { groups. Then the nursing students discuss the code of ethics with their teachers by } \\
\text { the patient's bedside. }\end{array}$ \\
\hline 17 & - Discussion of past sessions & Conclusion \\
\hline
\end{tabular}

For the different dimensions of moral sensitivity, the highest scores were in these areas: Relational orientation with the patient, ethical meaning to ethical decisions, expressing benevolence. Comparison of the total score for emotional sensitivity before and after intervention based on the paired t-test showed a significant statistical relationship ( $p=0.02$ ). Before intervention, the majority of students obtained average moral sensitivity scores, and after the 17 sessions, the ethical sensitivity score of students increased to moderate or high levels (Table 3).

\section{Satisfaction of nursing students with the ethics games}

At the end of the nursing ethics course, repeated-measure ANOVA was used to measure student satisfaction with the games. The average student satisfaction score for each session was more than 4.4 (out of a total of 5; see Table 3). As seen in Table 3, the Card Sorting and Drawing or Art Production games earned the highest scores from students; the Role Playing, Talking-in-Pairs, Hot Seat, Health Travel, and Socratic Debate games ranked next, in that order. Because there was no sphericity between meanings, the Greenhouse-Geisser 
correction was used and showed no significant trend between the means of the sessions ( $p=0.66$; Table 4$)$.

\section{Discussion}

Using games to teach professional ethics principles in terms of awareness of how to communicate with the patient and the use of ethical concepts in moral decisions had a positive effect.

In agreement with our findings, the Ertuğ et al (26) study in Turkey also showed that the moral sensitivity of nurses is influenced by education and level education. The results of the Kang study (27) in Korea also indicated that ethics education is necessary to create a desirable moral value system among nursing students. In order to enable them to maintain ethical behaviour in the clinical environment, their judgement and moral sensitivity should be improved through education. In the present study, the purpose of ethics education through games was to prepare nursing students to deal with ethically challenging situations in the clinical environment. For this reason, we simulated real-life situations in the games for the students to improve their awareness and learn how to deal with moral difficulties in the context of nursing practice.

In line with our results, other studies conducted by DeSimone (28) and Baykara et al (8) also reported that by changing the curriculum of nursing students and expressing examples of moral defects and correcting them, we can increase the awareness and ability of nursing students and prepare them for clinical environments to distinguish ethical defects and make ethical decisions. The game exploring types of physician-nurse-patient communication models (role playing communication with patients, other nurses, and physicians) prepared the nursing students to speak up and defend their decisions in ethically challenging situations.

Nursing students enter the clinical environment from their second semester of their second year and encounter ethical dilemmas in situations and are always looking for answers to these ethical dilemmas. The strength of this study was that it used the experiences of the students from their clinical environment to think about ethics. Johnsen et al (29) opined that the games should be based on participants' knowledge and experience. Therefore, it is better to use the syllabus as well as an assessment of nursing students' skills to determine the

\begin{tabular}{|l|l|l|l|}
\hline \multicolumn{4}{|c|}{$\begin{array}{c}\text { Table 2: Comparison of moral sensitivity scores by dimension } \\
\text { before and after training in professional nursing ethics }\end{array}$} \\
\hline Components & $\begin{array}{l}\text { Before } \\
\text { training } \\
\text { (M } \pm \text { SD) }\end{array}$ & $\begin{array}{l}\text { After Training } \\
\text { (M } \pm \text { SD) }\end{array}$ & $p$ value \\
\hline Autonomy & $7.6 \pm 1.61$ & $7.33 \pm 1.37$ & 0.45 \\
\hline Relational orientation & $14.10 \pm 2.02$ & $16.33 \pm 2.64$ & 0.000 \\
\hline Professional knowledge & $3.73 \pm 1.98$ & $3.23 \pm 1.79$ & 0.19 \\
\hline Experiencing moral conflict & $7.53 \pm 2.01$ & $7.80 \pm 2.01$ & 0.59 \\
\hline Ethical meaning & $11.53 \pm 2.79$ & $13.03 \pm 1.87$ & 0.003 \\
\hline Expressing benevolence & $16.17 \pm 3.49$ & $16.83 \pm 3.14$ & 0.46 \\
\hline Total moral sensitivity & $60.67 \pm 7.5$ & $64.57 \pm 6.9$ & 0.02 \\
\hline$p<0.05$ considered significant & & & \\
\hline
\end{tabular}

\begin{tabular}{|l|l|l|}
\hline $\begin{array}{c}\text { Table 3: Comparison of range of moral sensitivity scores before } \\
\text { and after professional ethics training }\end{array}$ \\
\hline Moral sensitivity scores & Before training & After training \\
\hline Low moral sensitivity (0-50) & $6.7 \%$ & $3.3 \%$ \\
\hline Moderate moral sensitivity (51-75) & $93.3 \%$ & $86.7 \%$ \\
\hline High moral sensitivity (75-100) & $0 \%$ & $10 \%$ \\
\hline
\end{tabular}

content of the game.

In this study, the card sorting game achieved high satisfaction among students, and the exercise benefited from the experiences of the students. In this game, the students wrote the ethical dilemmas that they encountered in the clinical environment as case studies on the cards. They also wrote ethical principles and standards that should be followed in dealing with the cases on the other side of the cards. They then discussed the correctness of these principles in small groups and practiced the correct principles under guidance from the educators.

In line with our findings, Chang et al (30) also showed that the card game can simulate clinical scenarios and teach various skills, such as communication, teamwork, and technical skills. Playing the card game encourages participants to unite and try to respond to scenarios. Game cards can be used in any scenario or with any group of healthcare providers within a simulation. In this research, the experiences of students in their clinical environment was used in other games, such as Talkingin-Pairs, the Health Travel Game, and the Brain Storming Game, to enable them to discuss the ethical difficulties that they have likely encountered. The Drawing or Production Art Game was another game that created a lot of satisfaction among

\begin{tabular}{|l|l|l|}
\hline \multicolumn{2}{|c|}{ Table 4: Student satisfaction score for ethical game sessions } \\
\hline Types of games & $\begin{array}{l}\text { Session } \\
\text { number }\end{array}$ & $\begin{array}{l}\text { Satisfaction score } \\
\text { (M } \pm \text { SD) }\end{array}$ \\
\hline The "buzz groups" Game & 1 & $4.6 \pm 0.49$ \\
\hline The Brainstorming Game & 2 & $4.7 \pm 0.65$ \\
\hline The Card Sorting Game & 3 & $4.9 \pm 0.18$ \\
\hline The Health Journey Game & 4 & $4.7 \pm 0.65$ \\
\hline $\begin{array}{l}\text { Instructor lecture; scenario writing for } \\
\text { the Role-Playing Game }\end{array}$ & 5 & $4.5 \pm 0.85$ \\
\hline The Role-Playing Game & & $4.7 \pm 0.52$ \\
\hline The Talking-in-Pairs Game & 6 & $4.7 \pm 0.70$ \\
\hline $\begin{array}{l}\text { Instructor lecture; analysis of student } \\
\text { assignments from the previous session }\end{array}$ & 8 & $4.5 \pm 0.86$ \\
\hline $\begin{array}{l}\text { Instructor lecture; scenario writing for } \\
\text { the Hot Seat Game }\end{array}$ & 9 & $4.5 \pm 0.81$ \\
\hline The Hot seat Game & 10 & $4.7 \pm 0.44$ \\
\hline The Drawing or Art Production Game & 11 & $4.8 \pm 0.37$ \\
\hline The Socratic Debate Game & 12 & $4.7 \pm 0.52$ \\
\hline The Pass the Parcel Game & 13 & $4.6 \pm 0.72$ \\
\hline The Pass the Parcel Game & 14 & $4.6 \pm 0.89$ \\
\hline The Case Study Game & 15 & $4.4 \pm 0.93$ \\
\hline Field Visits / Educational Visits Game & 16 & $4.6 \pm 0.81$ \\
\hline Discussion of past sessions & 17 & $4.4 \pm 0.93$ \\
\hline Total satisfaction score & & $79.06 \pm 7.72$ \\
\hline & 7 & \\
\hline & & 4.5 \\
\hline
\end{tabular}


students. In this game, students depicted the basic principles of ethics and nursing standards as drawings. Each group of students also created a flag for their group and wrote a moral slogan that reflected ethical rules. Macer (19) reported that in this type of game, everyone has a different talent, and that the students considered painting ridiculous but that creative thinking and artistic talents of students can grow in groups and they can have new experiences.

In the present study, as seen in Table 1, a part of the nursing syllabus focuses on teaching Iran's codes of ethics, in which the students are taught about a set of concepts, terms, and laws of professional ethics that are made consistent with Iran's culture, language, and religion. Instead of teaching the students about Iran's codes of ethics through lecturing, the trainer used a field visits / educational visits game in order to teach the students the ethics code in the clinic. As a result, they could implement the code of ethics in how they related with the patients and were exposed to cultural, religious, and linguistic differences.

In Iran, nurses need to have cultural and linguistic qualifications to be able to work in a clinical environment. Culture and religious beliefs play an important role in establishing communication with patients. For example, female nurses take care of female patients and male nurses take care of male patients, and Muslim women have certain beliefs, attitudes, and perceptions that directly influence the delivery of healthcare services by them. These differences and other religious and cultural differences have caused publication of numerous systematic and comprehensive studies that focus on professional ethics and practical guidelines that are consistent with Iranian culture and religion(31,32). Consequently, a set of standards under the title of "Codes of Ethics" has been formulated (33). Iran's code of ethics has been published in numerous studies and approved by Iran's health ministry. These codes of professional ethics should be taught to all nursing students in Iran (34).

The present study indicates that it is better to teach nursing students how to use ethical codes in the real clinical environment. This goal can be achieved by educating and empowering nursing students(35). Stanley and Latimer (36) showed that although game play is one of the new teaching strategies and a useful tool for learning, a number of nursing educators have doubts about its usefulness or value in nursing education. Therefore, gaining insight about the tangible benefits of playing games is valuable. Educational catalogues can be used to introduce these methods, providing empirical evidence of how games are used to enhance the care of patients in the clinical environment and to enable students to achieve clinical competencies, provide high-quality care, and participate in group work

\section{Conclusions}

The main limitation of this study was the use of a single intervention group and the lack of a control group. This prevented accurate comment on a possible cause-effect relationship. The small sample size of students from only one university was another limitation of this study. One of the main advantages of this study was that use of game play was a satisfactory method of teaching ethics to the students. This study was able to create a cheerful environment for problem solving for the students and teach ethical challenges in a warm and friendly environment.

This study benefited from the combination of theoretical and practical teaching simultaneously, increased the ethics and satisfaction of nursing students, and made it easy for them to engage with complex and tedious issues. Game play is a useful approach to developing moral sensitivity among nursing students and sensitising them toward ethical issues in their professional field. It prepares them to deal with moral problems and make ethical decisions in the clinical environment. In this study we used the clinical experiences of the nursing students to teach them ethical values for realworld situations.

We suggest that another study be conducted with the addition of educational catalogues elaborating on ethical principles, especially for clinical scenarios, and we can also use "readyto-use" guides in leaflet form to encourage the application of ethical principles in patient care.

\section{Acknowledgements}

The researchers would like to thank the Malayer School of Nursing Education; the researchers also extend their appreciation to the Malayer instructors and nursing students.

\section{Conflicts of interest and funding: None to declare.}

\section{References}

1. Ebrahimi H, Nikravesh M, Oskouie F, Ahmadi F. Ethical behavior of nurses in decision-making in Iran. Iran J Nurs Midwifery Res. 2015 JanFeb;20(1):147-55.

2. Oh Y, Gastmans C. Moral distress experienced by nurses: a quantitative literature review. Nurs Ethic. 2015 Sep;22(1):15-31.

3. Jafari H, Khaghanizade M, Nouri JM, Nir MS. Developmental Strategies for Nursing Ethics Education. Med Ethics J. 2017 Jan;10(38):81-90.

4. Borhani F, Abbaszadeh A, Hoseinabadi-Farahani MJ. Moral sensitivity and its dimensions in Iranian nursing students. $J$ Med Ethics Hist Med. 2016 Dec;9(19):1-7.

5. Borhani F, Alhani F, Mohammadi E, Abbaszadeh A. Professional Ethica Competence in nursing: the role of nursing instructors. J Med Ethics Hist Med. 2010 Jul;3(3):1-8.

6. Lee $\mathrm{HL}$, Huang $\mathrm{SH}$, Huang $\mathrm{CM}$. Evaluating the effect of three teaching strategies on student nurses' moral sensitivity. Nurs Ethics. 2017 Sep;24(6):732-43.

7. Yeom HA, Ahn SH, Kim SJ. Effects of ethics education on moral sensitivity of nursing students. Nurs Ethics. 2017 Sep;24(6):644-52.

8. Baykara ZG, Demir SG, Yaman S. The effect of ethics training on students recognizing ethical violations and developing moral sensitivity. Nurs Ethics. 2015 Sep;22(6):661-75.

9. Nasrabadi AN, Joolaee S, Parsa-Yekta Z, Bahrani N, Noghani F,Vydelingum V.A new approach for teaching nursing ethics in Iran. Indian J Med Ethics. 2009 Apr-Jun;6(2):85-9.

10. Bruce A, Rietze L, Lim A. Understanding Philosophy in a Nurse's World: What, Where and Why?. Nursing and Health. 2014 May;2(3):65-71.

11. Park M, Kjervik D, Crandell J, Oermann MH. The relationship of ethics education to moral sensitivity and moral reasoning skills of nursing students. Nurs Ethics. 2012 Jul;19(4):568-80.

12. $\mathrm{Xu} \mathrm{J-h}$. Toolbox of teaching strategies in nurse education. Chinese Nursing Research. 2016 June;3(2):54-7.

13. Royse MA, Newton SE. How gaming is used as an innovative strategy for 
nursing education. Nurs Educ Perspect. 2007Sep-Oct;28(5):263-7.

14. Boozaripour M, Abbaszadeh A, Shahriari M, Borhani F. Ethical values in nurse education perceived by students and educators. Nurs ethics. 2018 Mar;25(2):253-63.

15. Lützén K, Nordin C, Brolin G. Conceptualization and instrumentation of nurses' moral sensitivity in psychiatric practice. Int J Methods Psychiatr Res. 1994. ;4(42):241-248.

16. Lutzen K, Dahlqvist V, Eriksson S, Norberg A. Developing the concept of moral sensitivity in health care practice. Nurs ethics. 2006 Mar;13(2):18796.

17. Abbaszadeh A, Borhani F, Moazen- Nematollahi L. The comparison of the level of moral sensitivity in nursing students and nursing staffs in Kerman in 1389. J Med Ethics. $2010 ; 4$ (12):39-54.

18. Karimi Noghondar M, Tavakoli N, Borhani F, Mohsenpour M. Ethical sensitivity: A comparison between the nursing students and nurses of Azad University. Iran J Med Ethics Hist Med. 2016 Feb;8(5):69-76.

19. Farasatkish $\mathrm{R}$, Shokrollahi N, Zahednezhad H. Critical care nurses' moral sensitivity in Shahid Rajaee Heart Center Hospital. Iran J Cardiovasc Nurs. 2015 Jun; 4(3) :36-45.

20. Hakim A. Nursing students' satisfaction about their field of study. $J$ Adv Med Educ Prof. 2014Apr;2(2):82-7.

21. Mills D, Alexander P. Small group teaching: a toolkit for learning. The Higher Education Academy. 2013 Mar.4-5

22. Edmunds S, Brown G. Effective small group learning: AMEE Guide No. 48 . Med Teach. 2010 Aug;32(9):715-26.

23. Aeen F, Heravi M, Ahmadi F, Tootoonchi M. Baccalaureate Nursing Curriculum: Its Adjustment with Burden of Diseases as "Disability Adjusted Life Years" in Iran. Iran J Med Educ. 2006;6(2):8-16.

24. Farsi Z, Dehghan-Nayeri N, Negarandeh R, Broomand S. Nursing profession in Iran: an overview of opportunities and challenges. Jpn J Nurs Sci. 2010 Jun;7(1):9-18.

25. Ertug N, Aktas D, Faydali A, Yalçin O. Ethical sensitivity and related factors of nurses working in the hospital settings. Acta Bioeth. 2014 Nov;20(2).

26. Kang S-W. The influence of ethics education on awareness of nursing students with no clinical experience regarding the code of ethics: A case study. Journal of Nursing Education and Practice. 2017 April; 7(10):12.

27. DeSimone BB. Curriculum design to promote the critical thinking of accelerated bachelor's degree nursing students. Nurse Educ. 2006 SepOct;31(5):213-7.

28. Johnsen HM, Fossum M, Vivekananda-Schmidt P, Fruhling A, Slettebo A. Developing a Serious Game for Nurse Education. J Gerontol Nurs. 2018 Jan;44(1):15-9.

29. Chang TP, Kwan KY, Liberman D, Song E, Dao EH, Chung D, et al. Introducing Teamwork Challenges in Simulation Using Game Cards. Simul Healthc. 2015 Aug;10(4):223-6.

30. Macer DR. Moral games for teaching bioethics: International Center for Health, Law and Ethics, Faculty of Law, University of Haifa; 2008.

31. Shahriari M, Mohammadi E, Fooladi MM, Abbaszadeh A, Bahrami M. Proposing codes of ethics for Iranian nurses: A mixed methods study. $J$ Mix Methods Res. 2016 Feb;10(4):352-66.

32. Sanjari M, Zahedi F, Aalaa M, Peimani M, Parsapoor A, Cheraghi MA, et al. Code of ethics for Iranian nurses. Iran J Med Ethics Hist Med. 2011 Sep;5(1):17-28.

33. Zahedi F, Sanjari M,Aala M,Peymani M, Aramesh K, Parsapour A, et al.The code of ethics for nurses. Iran J Public Health. 2013 Jan;42(Supple1):1-8

34. Maddineshat $M$, Hashemi $M$, Gharib $A$. The effect of implementing nursing ethics code as a combined plan, in the School of nursing and clinical setting, Bojnurd, North Khorasan Province (2013-2015). Bali Med J. 2018 April;7(1):27-34

35. Shapira-Lishchinsky O. Ethical dilemmas: the experiences of israeli nurses. Qual Health Res. 2009;19(11):1602-11.

36. Stanley D, Latimer K.'The Ward': A simulation game for nursing students. Nurse Educ Pract. 2011 Jan;11(1):20-5.

\title{
Relationship between autonomy and moral distress in emergency nurses
}

\author{
MOHSEN ABDOLMALEKI, SIMA LAKDIZAJI, AKRAM GHAHRAMANIAN, ATEFE ALLAHBAKHSHIAN, MOZHGAN BEHSHID
}

\section{Abstract}

Reducing nurses' autonomy can impair their decision-making and ability for appropriate interventions. Lowered independence

Authors: Mohsen Abdolmaleki (Mohsen_2068491@yahoo.com), MSc Student in Nursing, Student' Research Committee of Nursing and Midwifery Faculty, Tabriz University of Medical Sciences, Tabriz, IRAN Sima Lakdizaji (corresponding author --laks@tbzmed.ac.ir), Nurse Educator, Department of Medical Surgical Nursing, Faculty of Nursing and Midwifery, Tabriz University of Medical Sciences, Tabriz, IRAN; Akram Ghahramanian (ghahramaniana@ tbzmed.ac.ir), Assistant Professor, Department of Medical Surgical Nursing Nursing and Midwifery Faculty, Hematology and Oncology Research Center, Tabriz University of Medical Sciences, Tabriz, IRAN; Atefe Allahbakhshian (allahbakhshiana@tbzmed.ac.ir), Assistant Professor, Faculty of Nursing and Midwifery, Tabriz University of Medical Sciences, Tabriz, IRAN; Mozhgan Behshid (behshidm@tbzmed.ac.ir), Assistant Professor, Faculty of Nursing and Midwifery, Medical Education Research Centre, Tabriz University of Medical Sciences, Tabriz, IRAN.

To cite: Abdolmaleki M, Lakdizaji S, Ghahramanian A, Allahbakhshian A, Behshid M. Relationship between autonomy and moral distress in emergency nurses. Ind J Med Ethics. 2019 Jan-Mar:4(1)NS:20-5. DOI:10.20529/ IJME.2018.076.

Published online on October 6, 2018.

Manuscript Editor:Vijayaprasad Gopichandran

Peer reviewers: Kannan Thiruvengadam and C Priyadarshini

(c) Indian Journal of Medical Ethics 2018 hinders ethical reasoning, which may lead to moral distress. This descriptive correlation study investigates the relationship between professional independence and moral distress in 173 nurses working in emergency departments in Tabriz, Iran. Data were collected using questionnaires designed to assess professional autonomy and moral distress and analysed using descriptive and inferential statistics via the SPSS 13 software. The level of professional autonomy among emergency nurses was low (83.2 \pm 16.9$)$, and moral distress, moderate (7.43 \pm 3.52 ). A statistically significant negative relationship was reported between professional independence and the frequency of moral distress $(p=0.018)$. Bivariate analysis related professional autonomy with the frequency and intensity of moral distress. Multiple regression analysis showed that age significantly predicted moral distress (frequency, intensity, and total scores). Lack of autonomy hinders nurses from functioning effectively and efficiently in practice and even can lead to moral distress. Increasing professional independence and the use of experienced nurses as mentors in emergency settings to support younger nurses can help with the reduction of moral distress. 